\title{
SfII
}

\section{Studies in Second Language Learning and Teaching}

Department of English Studies, Faculty of Pedagogy and Fine Arts, Adam M ickiewicz University, Kalisz

\section{Getting to the bottom of $\mathbf{L}$ listening instruction: Making a case for bottom-up activities}

\author{
Joseph Siegel \\ M eiji Gakuin University, Tokyo, Japan \\ siegel@eco.meijigakuin.ac.jp
}

Aki Siegel

Rikkyo University, Tokyo, Japan

siegel@rikkyo.ac.jp

\begin{abstract}
This paper argues for the incorporation of bottom-up activities for English as a foreign language (EFL) listening. It discusses theoretical concepts and pedagogic options for addressing bottom-up aural processing in the EFL classroom as well as how and why teachers may wish to include such activities in lessons. This discussion is augmented by a small-scale classroom-based research project that investigated six activities targeting learners' bottom-up listening abilities. Learners studying at the lower-intermediate level of a compulsory EFL university course were divided into a treatment group $(n=21)$ and a contrast group $(n=32)$. Each group listened to the same audio material and completed listening activities from an assigned textbook. The treatment group also engaged in a set of six bottom-up listening activities using the same material. This quasi-experimental study used dictation and listening proficiency tests before and after the course. Between-group comparisons of t-test results of dictation and listening proficiency tests indicated that improvements for the treatment group were probably due to the BU intervention. In addition, results from a posttreatment survey suggested that learners value explicit bottom-up listening instruction.
\end{abstract}

Keywords: listening pedagogy; bottom-up listening activities; dictation; listening proficiency 


\section{Introduction}

Among the four main language skills (i.e., listening, speaking, reading, and writing), listening may be the most important skill for second language (L2) users. Listening in an L2 is the main way in which learners expand their understanding of spoken input and therefore is an essential element of language learning (Field, 2008a). According to Dunkel (1991), "[aural comprehension] is very possibly of more use to most learners of foreign languages than is speaking competence" (p. 436). What is more, the importance attributed to $L 2$ listening continues to increase in international communication, business, testing, and Englishas-a-lingua-franca interactions (Richards \& Burns, 2012; Rost, 2014).

Despite the importance of listening, teachers may be unfamiliar with a range of activities that effectively develop the necessary subskills and strategies that lead to competent listening (Nemtchinova, 2013). M oreover, based on findings from questionnaires, class observations, and teacher interviews, language educators are often lacking in practical approaches, techniques and activities that they can apply in their classrooms (Graham, Santos, \& Francis-Brophy, 2014; Graham, Santos, \& Vanderplank, 2011). Further, teachers who turn to textbook teacher manuals for help may find little support for listening (Field, 2012). Like their teachers, students also struggle with listening in the classroom, and they usually identify listening as the most difficult skill to acquire (e.g., Field, 2008a; Renandya \& Farrell, 2011).

\section{Literature review}

\subsection{Understanding speech}

Until the late 1980 's, listening was generally viewed as a receptive ability in which the listener played a passive role. However, more recent perspectives on $\mathrm{L} 2$ listening comprehension recognize that the listener engages actively in interpreting a speaker's messages and plays a pivotal role in the communication process (e.g., Anderson \& Lynch, 1988). An ordinary belief about listening may be that it is a single process, but this stance would be overly simplistic. A more accurate and refined understanding defines listening not as a single process but as a series of integrated processes that must combine for successful listening comprehension (Lynch, 2009). This series of operations includes distinguishing speech from nonspeech, perceiving phonemes and individual sounds, parsing the speech stream into individual words and meaningful chunks, recognizing grammatical patterns and discourse structure, inferring a speaker's intentions, incorporating one's knowledge of the topic and situation, and understanding all 
of these within the context of speech (e.g., Brown, 2011; Buck, 2001; Field, 2003). Represented in this list of processes are psychological skills, schematic knowledge, interpretational abilities, as well as linguistic, general, and contextual knowledge (e.g., Lynch, 2009; Rost, 2002; Wu, 1998). Thus, to achieve overall listening comprehension in real time, a listener needs to draw on myriad capabilities, each at least to some degree.

These processes can be categorized into the bottom-up (BU) and topdown (TD) views of listening, two notions that are recurrent in the literature. BU processes are essentially "stimulus-driven" (Howard, 1983, p. 291); that is, an acoustic signal must enter the ear before they can begin. In contrast, TD processes are "conceptually-driven" (Howard, 1983, p. 292) and include the listener's background knowledge and contextual understanding.

These notions are summarized below and represented in Figure 1, which reflects the perceptual processing, parsing, and utilization stages of Anderson's (2005) model of aural comprehension. The arrows in Figure 1 represent the directionality of processing and are double-ended to demonstrate that these cognitive operations may overlap or occur (nearly) simultaneously.

Top-down processing (conceptually-driven; moving towards BU)
Schema (underlying structure that links parts of the text)
Script (a sequence of events or discrete parts of the text)
Concept (a mental representation of the text)
Meaningful chunks and phrases*
Pottom-up processing (stimulus driven; moving towards TD)

Note. ${ }^{*}=$ These are the BU aspects the present study is concerned with.

Figure 1 Directionality of TD and BU processing

TD processing involves the breaking down of a whole message into individual parts. Listeners draw on prediction, inference, and contextual skills, among others, to interpret the speaker's meaning (Lynch \& M endelsohn, 2002). TD processing also comprises prior knowledge, including topic, genre, and cultural understanding (Vandergrift, 2004). Each listener's TD processing is distinct and dependent on context, individual knowledge, and life experience, which present themselves through predictions, hypotheses and expectations.

At the higher end of Figure 1, notions of schema activation and script 
knowledge are similar to Anderson's (2005) concept of utilization in that listeners take what they hear and apply it to their background knowledge and life experience. Because concepts such as utilization, schema, and background knowledge are distinct for each listener, TD processing operations and outcomes likely vary. While TD processing receives considerable attention in listening pedagogy and textbooks in the forms of predictive exercises and activation of background knowledge, relying solely on TD listening can result in misunderstandings (e.g., Lynch, 2009). Therefore, this paper argues for the benefits of directly addressing the $\mathrm{BU}$ skills, shown at the lower part of Figure 1.

At the lowest level of Figure 1 is phoneme recognition, which is related to Anderson's notion of perceptual processing, as both concepts focus on individual sounds and sound combinations. Perceptual processing is also required for parsing the speech stream into words and chunks, for listeners need to recognize word beginnings and endings. Recognition of phonemes and parsing of the speech stream can only occur once a stimulus (i.e., aural input) is recognized.

In contrast to TD processing, BU processing involves "perceiving and parsing the speech stream at increasingly larger levels beginning with auditory-phonetic, phonemic, syllabic, lexical, syntactic, semantic, propositional, pragmatic and interpretive" (Field, 2003, p. 326). Listeners build meaning in a cumulative way whereby individual phonemes combine to form more substantial meaningcarrying expressions (Vandergrift, 2004). BU processing acts on incoming speech to decipher message content through the auditory signals the speaker sends.

It is generally agreed that listeners do not exclusively employ either of these approaches; rather, an interactive combination of the two is ideal (e.g., Lynch \& Mendelsohn, 2002; Yeldham \& Gruba, 2014). Contextual guesswork (i.e., TD) needs to be combined with acoustic and linguistic perception and interpretation (i.e., BU; Lynch, 2009). As Lynch and M endelsohn (2002) point out, every listener needs to attend to acoustic input in order to aid their TD processing and to confirm, reject, or revise any hypotheses they have formed.

While BU and TD are common views of the listening process, several other factors are also involved in and impact listening competence. These factors include the context of the listening event, the listening task or purpose, affective elements that are distinct for each listener, social abilities that may include requests for clarification or tolerance for misunderstandings, and cultural expectations for oral and aural communication (Flowerdew \& Miller, 2005). All of these components (e.g., BU, TD, social and contextual factors) integrate and contribute to listening competency.

Based on the conceptualization of listening discussed above, several different elements are involved in aural comprehension. These include TD, BU, and 
the ability to demonstrate successful comprehension in real time (i.e., by responding appropriately to a speaker or task). Therefore, a logical expectation would be that these areas of listening would all be addressed in L2 listening lessons. The current state of affairs, however, indicates a pedagogic imbalance (e.g., Field, 2008a; Siegel, 2014; Vandergrift, 2010).

\subsection{Common practices}

M uch of $\mathrm{L} 2$ listening pedagogy involves extensive focus on TD elements or considerable emphasis on answering comprehension questions (e.g., multiple choice, fill-in-the-blank, etc.), or a combination of both. These approaches often overlook the "nuts and bolts that [enable] the listening process to take place" (Field, 2008a, p. 30). In other words, teaching approaches often place importance on what the listener brings to the listening event (i.e., aspects near the TD portion of Figure 1, such as background knowledge, personal experience, etc.) or on students' ability to demonstrate comprehension by correctly answering discrete item questions. These points of emphasis overshadow, in particular, phoneme recognition and parsing capabilities, the elements represented near the BU position in Figure 1. Furthermore, as pointed out by several recent publications (e.g., Siegel \& Siegel, 2013; Vandergrift \& Goh, 2012; Yeldham \& Gruba, 2014), research into listening pedagogy has typically overlooked studies on BU pedagogy.

\subsection{Pedagogic suggestions}

Recently, pedagogic literature on $\mathrm{L} 2$ listening has begun to promote BU activities that explicitly and directly focus learner attention on the phonological properties and segmentation of the speech stream (e.g., Al-Jasser, 2008; Siegel \& Siegel, 2013; Field, 2008a; Vandergrift \& Goh, 2012). However, recent studies of $\mathrm{L} 2$ listening instruction have revealed that many teachers rarely incorporate $\mathrm{BU}$ processing in their listening lessons (e.g., Graham, Santos, \& Francis-Brophy, 2014; Siegel, 2014). An expansion in pedagogic practices to include more BU techniques is needed as this area is typically overlooked and because many of the listening difficulties $L 2$ learners experience have been attributed to BU obstacles. These difficulties include an inability to notice spoken forms of words learners know in print and trouble segmenting the speech stream into manageable chunks and phrases (Goh, 2000). Beyond these are issues related the speed of L2 speech and the often challenging phonological blending of sounds that occur during fluent speech (Vandergrift \& Goh, 2012). In response to these challenges, commentators have called for more attention to be given to BU processing as a crucial element for developing L2 listening skills (e.g., Field, 2003). 
Pedagogic techniques for the classroom include focusing on phoneme perception by accounting for aspects such as segmental and suprasegmental features, intonation patterns and phonetic clustering (e.g., Al-Jasser, 2008; Yeldham \& Gruba, 2014). Also recommended are activities that target segmenting the speech stream into chunks, recognizing where words begin and end, and building up lexical predictions based on the previous words in an utterance (e.g., Field, 2008a). While these and other BU activities have been marketed in L2 teaching and learning literature, the extent to which they aid the development of learners' BU abilities in the classroom remains an area in need of further investigation. Intuitively, many of these exercises would seem to be valuable additions to any teacher's listening instruction repertoire. However, they need to shift from the conceptual level of the literature to the practical classroom context.

\subsubsection{The importance of BU processing for $L 2$ listeners}

First language (L1) users develop phonetic recognition and word segmentation skills early in life and without conscious attention (e.g., Vandergrift \& Goh, 2012). While this development occurs naturally in the L1, direct instruction and practice for similar skills (e.g., phonetic clustering norms, lexical segmentation) in the L2 may be beneficial. Field (2008a) points out that the objective of teaching learners how to manage the speech stream centers on learners being able to more closely approximate the automatic decoding processes employed by skilled listeners. The crucial importance of the acoustic signal needs to be acknowledged in $L 2$ listening as equally (or perhaps more) important than TD and contextual knowledge (Field, 2003), and in order to do so instructors may need to specifically target those skills that allow learners access to the messages coded within the speech stream.

By including BU activities in their classrooms, $L 2$ teachers can help students overcome phoneme, word recognition and segmentation problems that frustrate many learners, particularly at lower levels (Goh, 2000). In addition, learners need accurate $\mathrm{BU}$ abilities in order to compare incoming input with the hypotheses and expectations they develop through TD processing (Lynch \& Mendelsohn, 2002). Moreover, perception and parsing activities can raise learners' awareness of acoustic pronunciation connections and variations of spoken language (Vandergrift \& Goh, 2012). Likewise, Field (2008a) observes that improving learners' ability to analyze the speech stream brings them closer to being skilled listeners who can accurately and automatically decode incoming speech, understand and utilize cotext (what has been said previously in a text), and free up valuable cognitive resources. The fundamental nature of listening involves proficiency in perceiving and parsing the speech stream; therefore, the benefits mentioned above warrant exploration of direct BU instruction techniques in $\mathrm{L} 2$ classrooms. 


\subsubsection{Studies of aural BU processing}

From a psycholinguistic perspective, several studies have increased our understanding of BU processes and the important role they play in $\mathrm{L} 2$ listening. These studies have attempted to isolate BU processes such as phoneme discrimination and lexical parsing, as well as to focus on relationships between both TD and BU processing and L1 and L2 phonotactics. Field (2003) conducted a study concentrating on problems of lexical segmentation and word boundary identification, which highlighted the importance of accurately parsing the speech stream. Field (2004) also investigated the potential conflict between TD and BU approaches in order to determine which was more influential. Using three separate experiments, learners were tested as to whether TD processes would override BU evidence from the input. The experiments consisted of word lists, sentences with high frequency words missing, and sentences with low frequency words. Results were mixed, but the word list experiment, which focused exclusively on phonetic perception, suggested that many learners attended closely to BU evidence.

Field (2008b) continued this line of research by investigating whether learners differentiate between function and content words as they deal with the incoming speech stream and found that the latter receive much more recognition than the former. This was in spite of the fact that function words appeared with more frequency in the texts used in the experiment. While content words typically carry more meaning, and therefore warrant significant attention, there are times when function words are important; for example, "compare I'm looking at the photos with I'm looking for the photos" (Field, 2008b, p. 429). To draw attention to function words, the author suggests brief awareness raising exercises targeting the problematic words or sounds. These controlled studies are valuable in their advancement of our understanding of L2 aural processing and serve to highlight the need for attention to BU processing in the L2 classroom.

Research on BU activities has gradually moved from more controlled experiments to the practical context of the classroom. Using a quasi-experimental pretest-treatment-posttest design, Al-Jasser (2008) investigated the possible transfer of $\mathrm{L} 1$ phonotactic conventions to an $\mathrm{L} 2$. The treatment group received additional BU instruction compared to the contrast group (see Appendix A for a summary of the BU instruction). To assess phonetic clustering awareness and lexical segmentation, a word spotting task in which participants were asked to identify words embedded in nonsense sequences was employed. Findings showed that L1 phonotactic conventions transferred to the L2, suggesting that explicit BU instruction for $L 2$ conventions is needed and that learners can be taught to utilize certain English-specific phonotactic cues. 
Using a case study approach, Yeldham and Gruba (2014) followed six Taiwanese learners in order to monitor their development during a course that emphasized BU skills. After first establishing learner preference as either predominantly TD or BU, students received a coordinated sequence of BU instruction (see Appendix A). Although individual students benefitted from some aspects of the instruction, overall findings showed little improvement for most of the students, with some students expressing boredom with BU rules and conventions. The authors concluded that a more interactive instructional style that incorporates BU and TD listening strategies would be preferable. As this study focused on only six participants, individual learner characteristics and preferences may have affected the findings.

\subsection{BU activities as classroom practice}

The previously mentioned studies have identified important stages of BU processing and attest to the mounting evidence that suggests BU processes are crucial for learners. In other words, studies suggest that teachers can teach learners "how to" listen and that such instruction would be beneficial (Nation \& Newton, 2009). A shift in the literature from comprehension-based approaches and TD emphasis toward more attention to BU processing, highlighted by works such as Field (2008a) and Vandergrift (2010), has the potential to affect the way listening is taught in L2 classrooms.

In theory, before accurate comprehension of fluent speech can be attained, learners need to develop BU skills that will help them decode input and need guidance to develop phonotactic and segmentation skills in the L2 (Al-Jasser, 2008). As BU evolves, overall comprehension of meaning and the ability to compare hypotheses generated from TD with actual acoustic input will improve. While the authors of this paper believe the pedagogic suggestions and activities related to BU processing expressed in the literature have pedagogic value, they need to be trialed more extensively in classrooms to determine the effects they may have on $\mathrm{L} 2$ listener development, both in terms of BU abilities and overall comprehension. Therefore, the present study was designed to determine whether explicit BU processing activities help learners' $L 2$ listening ability and how learners perceive such activities.

\section{The study}

In the initial stage of this project, Siegel and Siegel (2013) explored the use of a group of BU activities with two separate university listening classes in Japan. While that study demonstrated significant increases on dictation tests and 
learners' positive perceptions of the activities, the research design did not include a contrast group. As such, the study did not specifically show that learners' dictation test scores improved as a direct result of the BU activities. A second shortcoming was that the study did not employ a test of overall listening proficiency. Thus, additional research was designed to negate the conditions that left the previous study open to criticism.

\subsection{Research design and aims}

The present study aims to build on the study by Siegel and Siegel (2013) by refining the research design while incorporating the same set of BU activities. Although the skill of listening is complex and multifaceted, the focus of the present study was specifically on BU processing instruction and its role in facilitating listening competency. In order to investigate the effects of BU activities on university EFL learners' ability to understand aural input, this small-scale classroombased research adopted a quasi-experimental research design targeting the following research questions (RQs):

1. Does explicit BU instruction affect Japanese university EFL learners' listening ability as demonstrated by dictation tests in betweengroup comparisons?

2. Does explicit BU instruction affect Japanese university EFL learners' listening ability as demonstrated on the listening section of a language proficiency test (CASEC; for more detail see below) in between-group comparisons?

3. What are Japanese university EFL learners' perceptions of BU activities?

Null hypotheses of nonsignificant mean differences were constructed and tested for RQs 1 and 2. The dependent variables in the study were the dictation tests and the Computerized Assessment System for English Communication (CASEC) listening test scores, and the independent variable was the type of instruction. A posttreatment questionnaire was administered to address RQ 3. Details of these procedures are discussed below.

\subsection{Participants}

Participants in the study were enrolled in a compulsory EFL program at a university in Japan. All had similar cultural backgrounds and had received approximately six years of EFL education at the junior high and high school levels. Based on their scores on an English language proficiency test (CASEC), these students 
were assigned to classes at the lower intermediate level of the EFL program (approximately A2 CEFR level), which consisted of a listening/speaking and reading/ writing course.

The present research focused on the listening/speaking course, in which the textbook Let's Talk 1 (Jones, 2008) was used for all classes involved in the study. The listening component of this course consisted of textbook listening exercises, interactive activities and weekly quizzes. As it was not possible to control for incidental out-of-class English listening opportunities (e.g., internet use, conversations with English speakers on campus), it is likely that student exposure to oral English outside the classroom varied.

Three classes, totaling 53 students, took part in the study. The contrast group (CG) included 32 students in two different classes taught by two separate teachers. The CG teachers followed set class materials and activities, which included assigned textbook and audio materials, and administered pre- and postcourse dictation and CASEC tests. They taught the listening component of their classes without a special BU intervention. Postsemester discussions between the CG teachers and the authors indicated that the CG teachers followed the set textbook listening activities, which included ticking boxes, table completion, gap-fill, and matching exercises. The textbook did not include any listening strategy advice or explicit focus on spoken English (such as blends, contractions, etc.). The CG teachers used a variety of other activities, including self-made information-gap listening exercises, work with audio scripts, and use of additional audio/video materials, which varied by teacher.

The treatment group (TG) was taught by a third teacher (one of the authors) and included 21 students. Students in the TG practiced listening through the same assigned textbook as the CG, but instruction also included specific BU activities. Each listening/speaking class (for both the CG and TG) met twice a week for 90 minutes during the semester, for a total of 30 class periods.

\subsection{Procedure and tools}

For this study, the construct of the effects of explicit BU instruction was operationalized through student performance on dictation tests and the CASEC test, and student perceptions were measured by a questionnaire. Due to the pedagogic orientation of this paper, the authors felt it appropriate to include both empirical test results in conjunction with self-reported learner perspectives. The research design presented in Figure 2 consisted of the following stages: (a) precourse dictation test for both the CG and TG; (b) standard textbook listening activities for both the CG and TG; (c) explicit BU activities, according to a set weekly schedule, for the TG; (d) postcourse dictation test for both groups; (e) postcourse questionnaire for the TG. 

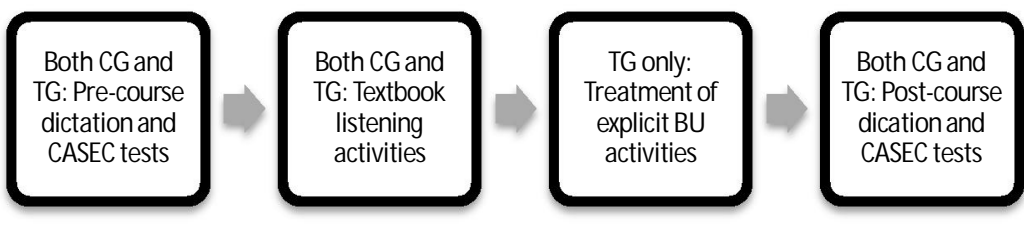

Figure 2 Research procedure

\subsubsection{The dictation test}

The main rationale for using a dictation test in this study was its capacity to provide evidence of students' BU processes, specifically their phonological perception and lexical segmentation skills. Flowerdew and Miller (2005) point out that dictation is an integrative testing technique and is a "synthesis of the speech perception process at the phonological, syntactic, and semantic levels" (p. 199). For that reason, dictation would seem to correspond with the definition of bottomup processes, which includes auditory-phonetic, phonemic, and syntactic aspects (e.g., Field, 2003). Thus, dictation is one way of investigating the decoding skill (Buck, 2001; Field, 2008b). Though their use is debatable due to concerns about scoring procedures, equal emphasis on all words, decontextualization, and lack of "real world" application, dictation tests were used because they provide visual evidence of perceptual processing and parsing skills and matched the BU instructional focus of the research. That is, they require listeners to exercise and provide visual evidence of phoneme perception and parsing abilities that are not explicitly evident when other instruments such as tests of overall listening comprehension are used.

The 100-word dictation test was on the topic of daily routines, which was believed to be a concrete and relatable topic for the participants. The dictation script (see Appendix B) contained several features of spoken English, such as elision (e.g., going to, gonna; at about, adabout), and collocations common to the textbook used by the TG and the CG (e.g., go to school; use the train). A digital recording of the dictation script was made by a native-speaking teacher who had no other involvement in the project. This was done to negate any student exposure to the voice on the recording. The script was read twice: once with a 10-second pause between sentences and then once at natural speed without extended pauses. The students listened to the recording in class and were instructed to write down as many words as they could in English. The same dictation task was used for both the pre- and postdictation test.

Both the pre- and postcourse dictation tests were scored by one of the authors and two trained raters who had no other involvement in the project. Dictation papers were compared to the original script and the total number of words was counted. Each word was worth one point, for a total of 100 points. 
Minor spelling mistakes (such as "tost" for "toast") were counted as correct when students had correct lexical segmentation and a close phonetic approximation of the target word (as suggested in Buck, 2001; Field, 2008b). The Pearson correlation coefficient for interrater reliability was 0.993 .

\subsubsection{The CASEC listening test}

The CASEC test is an English language proficiency test developed by the Society for Teaching English Proficiency Inc. (STEP), the largest testing institution in Japan. The test is completed online and consists of four sections: vocabulary, phrasal expression and usage, listening for main idea, and listening for specific information. Each test section is worth 250 points, with the maximum overall score of 1000 . The first three sections are multiple choice, and the final section is typed dictation (see Nogami \& Hayashi, 2010 for more details on the test). This test was used because it contains both a global listening comprehension component (Part 3, a listening comprehension section where students are required to answer 17 multiple choice main idea questions) as well as a section that focuses on BU processing and specific information (Part 4, an 11-item cloze test section where students listen for details and fill in missing words of a sentence or dialogue). Scores for Parts 3 and 4 were combined (hereafter referred to as the CASEC listening test), with a maximum point total of 500 , and this overall listening section score was used for analysis.

\subsubsection{The questionnaire}

To determine student perceptions of the BU activities, a posttreatment questionnaire was given to the TG. This bilingual survey was presented in students' L1 and English. Students were asked about their confidence in listening and about which BU activities may have helped their listening ability. This survey also contained Likert scale options (agree, somewhat agree, somewhat disagree, and disagree) pertaining to learners' perceived listening improvement as a result of each BU activity and their enjoyment thereof.

\subsection{BU instructional treatment}

The following BU activities were chosen because they address different levels of $\mathrm{BU}$ (e.g., phoneme recognition, lexical segmentation and chunking), which correspond to Anderson's (2005) notions of perceptual processing and parsing, as well as to the elements of BU processing identified earlier in Figure 1. The activities included in this study were: 
- Counting words: Based on a source text (e.g., textbook audio material or authentic video), the instructor selects sentences. Then, the teacher either reads or plays the sentences one at a time. Learners count the number of words they hear, typically counting on their fingers. Students can then compare their answer with classmates and the teacher. Because of contractions and connected speech, a range of answers may be acceptable. This can be a fun and functional technique for introducing various aspects of connected speech, and it emphasizes the phonetic perception of word beginnings and endings, a key skill in parsing the speech stream.

- Identifying lexical differences: The teacher selects sentences from a source text that include potentially problematic sound combinations or that exemplify some language feature. The original sentence from the text is designated "Sentence 1." The teacher also creates a variation on the sentence and labels the second sentence "Sentence 2." The teacher reads the two sentences and learners listen for any lexical differences. For instance, the teacher says: "1: I want to go to the supermarket. 2: I went to the supermarket." Learners report on the lexical difference. This activity can help learners' listening accuracy by focusing their attention at the acoustic phonetic level, where important grammatical and semantic information (e.g., tense, pluralization) is communicated. It can also be a useful method for reinforcing or recycling any recent grammar points covered in class through aural practice.

- Syntactic predicting: The instructor splits sentences from the source text either into single words or into common chunks. Students hear or see (on a blackboard or slide) one or two words at a time. The teacher encourages learners to guess the subsequent words or chunks through sentence syntax or semantic meaning. For example, students hear or see "I ____ and call out word candidates for the next space. Learners can also write down and compare their ideas before proceeding. Possibilities in this case should be limited to verbs. The teacher can give feedback on word candidates offered by students. The activity continues with the teacher adding the next word or phrase: "I have to ." The teacher repeats the process of eliciting student ideas and continues: "I have to help_____, "I have to help my parents with ", "I have to help my parents with the laundry." This activity can stimulate grammatical and syntactic knowledge that students may already have but have not linked to the predictive aspects of listening. Further, it draws learners' attention to parsing the speech stream as well as to listening for and creating chunks of language.

- Highlighting connected speech: Using the source text, the teacher chooses sentences with common sets of connected speech. First, a sentence is written on the board and students are encouraged to predict how the 
sentence might sound in spoken form. Then they hear the sentence spoken aloud (either spoken by the teacher or via a recording). Students can then participate in listen and repeat activities with the featured connected speech. This activity aids the development of phonetic perception and parsing of the speech stream, and it helps learners understand the differences between written and spoken language.

- Fill-in-the-blanks: This is a rather traditional way of focusing on specific words in a text. The written support provided, along with the listeners' syntactic and semantic knowledge, may help them complete the task. Such activities are often featured in listening textbooks but can also be created by teachers. They typically draw on phoneme perception and parsing skills, particularly when filling in a single-word gap. When the gap consists of more than one word, then the activity may also encourage accurate aural chunking. During this kind of BU instruction, students completed both single-word and multiword gap fills.

- Short transcriptions (adapted from Siegel \& Siegel, 2013): Students listen to short stretches of spoken language, either read or played by the teacher, and attempt to write what they hear. They can then discuss their work with classmates and the teacher. For the purposes of this study, short transcriptions consisted of brief question and answer combinations (e.g., "How are you today? I'm absolutely fantastic. Today's going to be a great day!"). These combinations were between 15-25 words and, although significantly shorter than the 100-word dictation test, the short transcription activity may have affected the dictation test results due to task familiarity.

Each activity was employed for approximately 10 minutes during three classes throughout the semester (e.g., the counting words activity was used for 10 minutes on three separate occasions for an approximate total of 30 minutes during the semester). When developing the activities for the TG class, the same assigned textbook audio used by the CG was utilized. Thus, the material covered by the CG and TG was the same; however, the TG also incorporated the additional BU activities. For approximately 10 minutes per class, CG teachers incorporated a variety of other activities, including self-made information gap listening exercises, work with audio scripts, and use of additional audio/video materials selected by the teachers. Therefore, the time spent on listening between the TG and CG was approximately the same.

\subsection{Analysis}

The overall alpha level was set at .05 and the statistical analysis was completed using SPSS version 21. Students with missing dictation or CASEC listening test 
scores were omitted from the data set. Consequently, the CG had 26 students and the TG had 18. To determine whether the listening abilities of the CG and TG differed, t tests were conducted on the pretest scores for both the dictation and CASEC instruments. The results showed no significant differences between the two groups on either the dictation test $(\mathrm{t}(42)=1.26, \mathrm{p}=.216)$ or on the CASEC listening test $(t(42)=1.76, p=.086)$. In other words, at the beginning of the semester, and prior to the treatment, the listening abilities of the two groups were similar. The following section will present the descriptive statistics and the results for the dictation and CASEC listening tests.

\section{Results}

\subsection{The dictation test}

Descriptive statistics for the dictation test are presented in Table 1. Two notable results are evident: the differences in the $M$ increases and the change in the SD between the two groups. The increase in the M for the TG (10.44) is noticeably higher than that for the CG (2.33), which may suggest that the BU instruction had at least some effect. As illustrated in Figure 3, the TG showed a sharp increase in their scores while the CG showed only a slight improvement. A paired samples t test for the TG showed a significant increase in the mean score $(t(17)=$ $-4.703, p<.001$ ) while the CG showed no significant differences $(t(25)=-1.228, p$ $=0.231$ ). Therefore, the increase in the test scores of the TG was not by chance.

Furthermore, the changes in SD values show that whereas students in the CG were similarly dispersed on both the pre- and postcourse dictation, those in the TG moved closer together and had more uniform scores on the posttest than on the precourse test. This suggests that the BU instruction had a positive effect on most of the students, and not just a small portion of the students.

Table 1 Descriptive statistics for the dictation test

\begin{tabular}{lrrrr}
\hline & & Pretest & & Posttest \\
\cline { 2 - 5 } Statistic & Treatment & & Contrast \\
$(n=18)$ & $(n=26)$ & $\begin{array}{r}\text { Treatment } \\
(n=18)\end{array}$ & $\begin{array}{r}\text { Contrast } \\
(n=26)\end{array}$ \\
\hline$M$ & 32.78 & 36.00 & 43.22 & 39.33 \\
SD & 11.39 & 10.68 & 9.07 & 10.37 \\
Skewedness & -0.05 & -0.44 & 0.55 & 0.26 \\
\hline
\end{tabular}




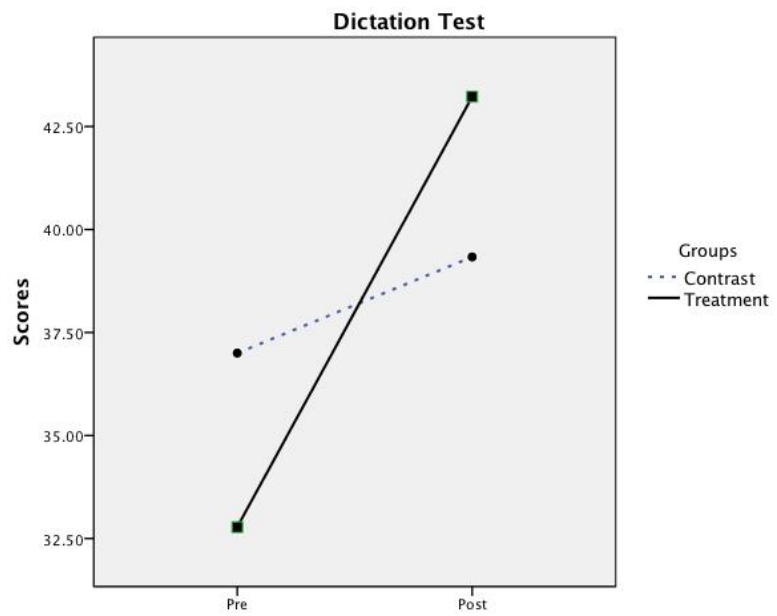

Figure 3 The dictation test results

\subsection{The CASEC listening test}

Results from the CASEC listening test provided data related to students' overall listening comprehension, which a dictation test may not be able to measure. The descriptive statistics for the student performance on the CASEC listening test are presented in Table 2. As Table 2 shows, despite starting with a lower mean score, the TG outperformed the CG on the CASEC listening test.

As shown in Table 2 and Figure 4, the CG scores slightly decreased while the TG increased significantly. Similar to the dictation test results, the effect of the $\mathrm{BU}$ instruction based on a paired samples t test was statistically significant $(\mathrm{t}(17)=-2.172, \mathrm{p}<.05)$, while the CG showed no significant differences $(\mathrm{t}(25)=$ $1.019, p=0.318$ ). Again, this finding indicates that the score increases were not only by chance.

Table 2 Descriptive statistics for the CASEC listening test

\begin{tabular}{lrrrr}
\hline & & Pretest & & Posttest \\
\cline { 2 - 5 } \cline { 4 - 5 } Statistic & Treatment & Contrast & Treatment & Contrast \\
$(n=26)$
\end{tabular}




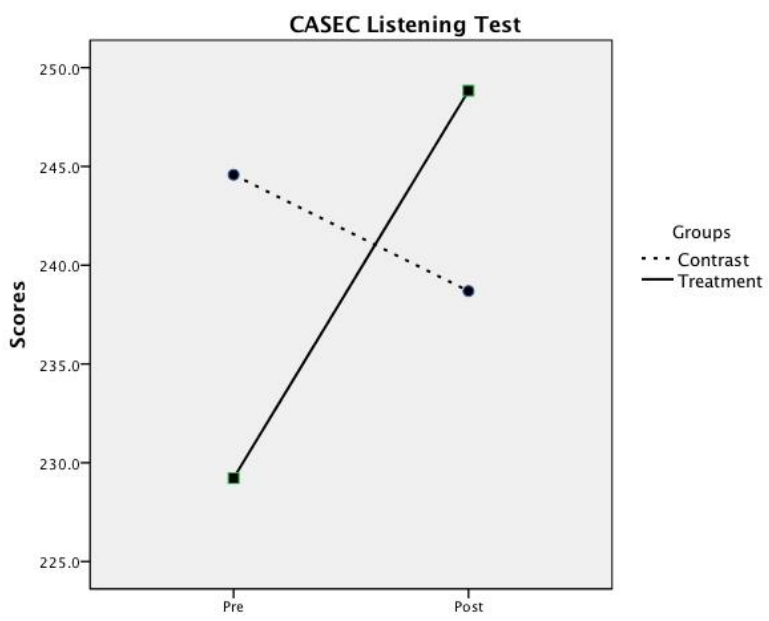

Figure 4 The CASEC listening test results

\subsection{The posttreatment survey}

Responses to the posttreatment survey (TG, $N=21$ ) showed overall positive attitudes toward the BU activities, with $67 \%$ (14) of students indicating that their confidence in listening had increased as a result of the BU exercises. The remaining 33\% of students felt their listening ability had stayed the same. Each activity received an individual score (1, strongly disagree; 4 , strongly agree) relating to enjoyment and perceived improvement stimulated by the activity. The average ratings for each activity were 3.33 and 3.28 , respectively, demonstrating that learners had overall positive perceptions of the BU activities.

\section{Discussion}

Findings from this study provide some justification for more pedagogic attention to BU processes, as promoted in the literature (e.g., Field, 2008a; Siegel \& Siegel, 2013; Vandergrift \& Goh, 2012). Statistical analyses showed no significant difference in listening ability between the CG and the TG at the beginning of the study. Therefore, gains on the dictation and listening proficiency tests suggest that the BU activities helped the TG students deal with the speech stream and improve their listening competency. Explicit practice for phonological and parsing skills are likely to have contributed to overall listening comprehension, as measured by the CASEC listening test. Student perceptions from the posttreatment survey served to augment the empirical gains, as the learners in the TG expressed positive opinions about the BU activities. However, we must exercise caution in finding any direct causal relationship due to the small number of participants. 
Both the empirical and survey findings are in line with those in Siegel and Siegel (2013), and the addition of a listening proficiency instrument (i.e., the CASEC listening test) provided further insights. Results from the present study demonstrate that BU activities may be effective in increasing learners' aural processing, are possibly related to improvements in overall listening comprehension to some degree, and were viewed as a valuable use of class time by most learners.

\subsection{Research question 1: Dictation results}

RQ1 focused on the effects BU instruction might have on dictation test scores, and the null hypothesis for this question was rejected. The analysis demonstrated that the explicit BU activities positively affected listener ability as displayed on the dictation test. This positive effect is evidenced by the relatively large gains made by the TG (10.44) compared to those of the CG (2.33). In addition, the SD of the TG scores decreased more than that of the CG. Based on these results, it can be said that the TG in this study improved more and did so more uniformly than the CG. Furthermore, the data from the t test showed statistically significant score increases on the part of the TG, indicating that their gains were not by chance but rather due to the $\mathrm{BU}$ intervention. These results suggest that BU instruction may be effective in significantly improving $L 2$ listening ability as measured by the dictation test.

Taken as a whole, the statistical data indicate that the incorporation of explicit BU attention, along with standard textbook listening activities, can increase learners' phoneme perception and parsing abilities more than the standard textbook activities alone. Therefore, we tentatively argue that BU skills such as perception, parsing, and chunking need direct and explicit attention in listening lessons, and more attention from 12 researchers, as these skills may not be acquired inherently and their acquisition may be accelerated by explicit activities. For example, activities such as those used in this study can help draw attention to spoken forms of the words students may already know in print but struggle to understand in the rapidly-incoming speech stream.

As Field (2008a) points out, BU processing and the decoding of the speech stream allow listeners to access the nuts and bolts that are crucial for listening. Without such a capacity, listeners will be rendered unable to compare the actual acoustic input they hear with the hypotheses and expectations they might build up through TD processing. As such, BU processing of aural language is essential, and the activities employed here seemed to aid learners in improving their perception and parsing abilities as demonstrated on the dictation tests. 


\subsection{Research question 2: The CASEC listening test results}

Regarding RQ 2, the BU instruction seemed to have some positive effect on the TG's listening proficiency test scores. Although there were no significant between-group differences prior to the course, when considering the noticeable gains by the TG and the decreasing scores by the CG on the CASEC listening test, these results may signal a need for more explicit BU instruction. Furthermore, the results may indicate the effect of $\mathrm{BU}$ instruction on overall listening comprehension. Despite starting lower than the CG, the TG outperformed the CG by more than 10 points on the posttest. Additional corroboration of this claim was provided by the t-test results, which also showed statistically significant gains by the TG, indicating that their gains were probably due to some specific pedagogic feature rather than to chance. The null hypothesis for RQ 2 was rejected as results showed that the BU instruction had a positive effect on overall listening proficiency for the TG in this study.

\subsection{Research question 3: Student perceptions of BU activities}

Student responses toward all six BU activities were generally positive, indicating that, from students' perspective, these exercises have a place in the L2 classroom. Learners not only thought that all of the activities were valuable in terms of their listening development, but they also reported that they were enjoyable. This notion of enjoyment should not be overlooked as many students traditionally view listening as the most difficult L2 skill to acquire (e.g., Field, 2008a; Renandya \& Farrell, 2011). Thus, to help motivation and to avoid repetitive, monotonous listening routines, these and similar activities may be welcome additions to lesson plans. Positive survey findings related to student perceptions of BU activities should be viewed as important learner feedback on listening instruction, which is often absent from the pedagogic literature.

\section{Pedagogic implications}

These findings are particularly important because they suggest that overall listening competency, not simply the ability to complete a dictation activity, can be bolstered by BU activities. It would seem that students with developed BU processing skills are able to access main ideas and specific details on the CASEC listening test more accurately than those whose BU processing abilities were not explicitly developed through the BU activities described earlier. The focus on BU properties of the $L 2$ may have aided the TG learners in recognizing individual phonemes, segmenting the speech stream, and comparing their listening expectations with the 
actual aural input, which in turn may have manifested itself in higher scores on the global comprehension questions and more specific detail focused items.

As such, these findings may be valuable for many in the $L 2$ teaching and learning community for a variety of purposes, including listening assessments and more general communication. The listening portions of tests such as the CASEC, as well as IELTS, TOEFL, and, TOEIC often require students to demonstrate their listening competency through both global and detail questions. Findings from this study suggest that teachers aiming to help their students to achieve high scores on these instruments may wish to include some explicit focus on BU processing, whether in the form of the activities used in this study or in different ways.

Moreover, conversational listening competency requires the ability to identify discrete items of information, such as names, dates, options, and reasons, in order to respond appropriately. Based on these findings, it appears that direct BU instruction may benefit learners who need to identify such details, whether on listening assessments or potentially during interpersonal communication. Such merits would not be limited to university EFL learners such as those in this study but could also extend to other educational contexts, including secondary school and/or compulsory L2 education. For example, given the interactive characteristics of several of these activities (e.g., physically counting words on one's fingers, seeing visual representations of spoken language, being prompted to predict upcoming words, comparing one's own written work or guesses with classmates), they may be particularly useful with younger learners or those who learn through active participation. While listening may be perceived as an individual, isolated, or passive portion of language classes, the straightforward activities described here can trigger an active and inquisitive atmosphere during listening instruction.

Based on this classroom-based research, we would tentatively argue that teachers can incorporate activities for aural BU processing that address the "how to" element of listening. The six activities discussed in this article are applicable to any listening text, from textbooks to semiauthentic materials to content aimed at native-level listeners. Furthermore, since these listening exercises are focused on the phoneme, parsing, and chunking levels, they are achievable for a range of proficiency levels, meaning the task expectations can be adjusted to give confidence to lower level learners and to challenge more advanced students. They also stimulate conversations about what learners believe they heard and provide opportunities for learners to discuss among themselves and with teachers their listening successes and challenges, which gives rise to valuable classroom dialogues linking to portions of Vandergrift and Goh's (2012) metacognitive pedagogic sequence. 


\section{Conclusion}

This paper described the use of a set of six BU activities from an empirical perspective and through student perceptions. Results showed that the TG outperformed the CG on both the dictation test and the CASEC listening test. Thus, the null hypotheses was rejected for RQs 1 and 2 . Findings from the survey addressed RQ 3, indicating positive learner perceptions of explicit BU listening practice.

Viewed as a whole, these results indicate that, even for the courses more concerned with global understanding and meaning-based aural comprehension, class work targeting phoneme, word, and chunk-level processing can be advantageous and provide a valuable supplement to other types of listening practice. Findings from the present study correspond to those found in the initial research phase (Siegel \& Siegel, 2013) in that dictation scores improved and survey results about the BU activities were positive. The present second phase of the study provided more insights by including a listening proficiency test and a contrast group, both of which highlighted gains made by learners in the TG.

Despite these positive findings, a number of weaknesses of the research must be acknowledged. First, the six BU activities were used as a collective set. This was done in order to address different levels of BU processing, such as phoneme recognition, lexical segmentation, and chunking, and to meet practical needs of class planning and delivery. However, due to this pedagogic decision, it was not possible to determine whether one particular activity is more beneficial than another. Future research may seek to focus specifically on individual $\mathrm{BU}$ activities to determine their merits. In addition, the short transcription activity may have affected the dictation test (though not the CASEC listening test) results through task familiarity. Either eliminating this activity or choosing an alternative evaluation method may improve future research. Thirdly, the research design did not strictly control for the listening component of the CG classes. Therefore, some activities and instruction experienced by the CG may have overlapped with the BU exercises used with the TG. To better account for classroom and teacher variables, similar research may be conducted with the same teacher planning and teaching both a CG and a TG. This design was not possible in the present research due to teaching assignments but would be an improvement in research design. Given the lenient research design and the limited sample size of the participant groups in this classroom-based research, the impact of the study should be taken as suggestive rather than definitive.

However, based on the increasing test results, the positive learner feedback, and our own pedagogic experiences, we believe the exercises presented in this paper should be added to other approaches (i.e., TD- or strategically-oriented) in order to provide more holistic, balanced, and integrated listening instruction (e.g., 
Yeldham \& Gruba, 2014). Still, even authors who promote a BU view of listening instruction (e.g., Goh, 2008; Vandergrift \& Goh, 2012) are aware of potential caveats, which teachers and researchers should consider. According to Goh (2008), when focusing on discrete phonemes, words, word combinations, or sentences, there is a danger of decontextualizing learning. Furthermore, Vandergrift and Goh (2012) point out that a lack of contextual support during listening can disadvantage learners. A third caveat comes from BU activities such as dictation, which may place equal prominence on each word and encourage word for word processing (Vandergrift \& Goh, 2012), neither of which are characteristic of listening in the real world. While there are some words of caution to heed, BU activities may be advantageous, yet currently underrepresented, in today's L2 classrooms.

The purpose of this study has been to determine whether BU activities promoted in the literature are effective and viable for the L2 classroom. Findings from dictation tests, a listening proficiency test, and a posttreatment survey suggest that they are, and that teachers aiming to help their students develop listening comprehension skills can do so by incorporating a variety of listening practice, including the BU activities described here along with more global listening exercises (already in regular use in many contexts) such as identifying main ideas, understanding speech as it relates to context, and utilizing background knowledge to facilitate comprehension. Therefore, we would tentatively argue for the incorporation of $\mathrm{BU}$ activities in conjunction with other pedagogic approaches to help learners feel that they have some command over rapidly incoming input, which they often feel is beyond their control. By isolating parts of the speech stream, learners can begin to see how the aural L2 can be managed systematically. While this study included only a selection of possible exercises to address BU processing, many other activities may prove equally or more valuable. It is hoped that this paper promotes additional descriptions of and investigations into $L 2$ listening pedagogy. 
References

Al-Jasser, F. (2008). The effect of teaching English phonotactics on the lexical segmentation of English as a foreign language. System, 36, 94-106. doi: http://dx.doi.org/10.1016/j.system.2007.12.002

Anderson, A., \& Lynch, T. (1988). Listening. Oxford: Oxford University Press.

Anderson, J. R. (2005). Cognitive psychology and its implications (6th ed.). New York: Worth.

Brown, S. (2011). Listening myths. Ann Arbor: University of M ichigan Press. Buck, G. (2001). Assessing listening. Cambridge: Cambridge University Press.

Dunkel, P. (1991). Listening in the native and second/foreign language: Toward an integration of research and practice. TESOL Quarterly, 25(3), 431-457. doi: $10.2307 / 3586979$

Field, J. (2003). Promoting perception: Lexical segmentation in L2 listening. ELT Journal, 57(4), 325-334. doi: http:// dx.doi.org/10.1093/elt/57.4.325

Field, J. (2004). An insight into listeners' problems: Too much bottom-up or too much top-down? System, 32, 363-377. doi: http://dx.doi.org/10.1016/j.system.2004.05.002

Field, J. (2008a). Listening in the language classroom. Cambridge: Cambridge University Press.

Field, J. (2008b). Bricks or mortar: Which parts of the input does a second language listener rely on? ELT Journal, 42(3), 411-432.

Field, J. (2012). Listening instruction. In A. Burns \& J. C. Richards (Eds.), The Cambridge guide to pedagogy and practice in second language teaching (pp. 207-217). New York: Cambridge University Press.

Flowerdew, J., \& M iller, L. (2005). Second language listening: Theory and practice. New York: Cambridge University Press.

Goh, C. (2000). A cognitive perspective on language learners' listening comprehension problems. System, 28, 55-75. doi: http://dx.doi.org/10.1016/S03 46-251X(99)00060-3

Goh, C. (2008). Metacognitive instruction for second language listening development: Theory, practice and research implications. RELC, 39(2), 188-213. doi: http:// dx.doi.org/10.1177/0033688208092184

Graham, S., Santos, D., \& Francis-Brophy, E. (2014). Teacher beliefs about listening in a foreign language. Teaching and Teacher Education, 40, 44-60. doi: http:// dx.doi.org/10.1016/j.tate.2014.01.007

Graham, S., Santos, D. \& Vanderplank, R. (2011). Exploring the relationship between listening development and strategy use. Language Teaching Research, 15(4), 435-456. doi: http://dx.doi.org/ 10.1177/1362168811412026 
Howard, D. (1983). Cognitive psychology: Memory, language and thought. New York: Macmillian.

Jones, L. (2008). Let's talk 1 (2nd ed.). Cambridge: Cambridge University Press.

Lynch, T. (2009). Teaching second language listening. Oxford: Oxford University Press. Lynch, T., \& M endelsohn, D. (2002). Listening. In N. Schmitt (Ed.), An introduction to applied linguistics (pp. 193-210). London: Arnold.

Nation, I. S. P., \& Newton, J. (2009). Teaching ESL/EFL listening and speaking. New York: Routledge.

Nogami, Y., \& Hayashi, N. (2010). A Japanese adaptive test of English as a foreign language: developmental and operational aspects. In W. J. v. d. Linden \& C. A. W. Glas (Eds.), Elements of adaptive testing (pp. 191-211). New York: Springer. Nemtchinova, E. (2013). Teaching listening. Virginia: TESOL International Association. Renandya, W. A., \& Farrell, T. S. C. (2011). "Teacher, the tape is too fast!" Extensive listening in ELT. ELT Journal, 65(1), 52-59. doi: http:// dx.doi.org/10.10 93/ elt/ccq015

Richards, J. C., \& Burns, A. (2012). Tips for teaching listening: A practical approach. White Plains, NY: Pearson.

Rost, M. (2002). Teaching and researching listening. Essex: Longman.

Rost, M . (2014). Listening in a multilingual world: The challenges of second language (L2) listening. International Journal of Listening, 28(3), 131-148.

Siegel, J. (2014). Exploring L2 listening instruction: Examinations of practice. ELT Journal, 68(1), 22-30.

Siegel, J., \& Siegel, A. (2013). Empirical and attitudinal effects of bottom-up listening activities in the $L 2$ classroom. ELT World Online, 5, 1-25.

Vandergrift, L. (2004). Listening to learn or learning to listen? Annual Review of Applied Linguistics, 24, 3-25.

Vandergrift, L. (2010). Researching Listening. In B. Paltridge \& A. Phakiti (Eds.), Continuum companion to research methods in applied linguistics (pp. 160173). London: Continuum.

Vandergrift, L., \& Goh, C. C. M. (2012). Teaching and learning second language listening. New York: Routledge.

Wu, Y. (1998). What do tests of listening comprehension test? A retrospection study of EFL test-takers performing a multiple-choice task. Language Testing, 15(1), 21-44. doi: http:// dx.doi.org/10.1191/026553298673885021

Yeldham, M., \& Gruba, P. (2014). Toward an instructional approach to developing interactive second language listening. Language Teaching Research, 18, 33-53. doi: http://dx.doi.org/10.1177/ 1362168813505395 


\section{APPENDIX A}

\section{Summary of recent BU intervention studies}

\begin{tabular}{|c|c|c|c|}
\hline Study & Aim & $\begin{array}{l}\text { Research } \\
\text { design }\end{array}$ & $\begin{array}{l}\text { Experimental BU } \\
\text { processing treatment }\end{array}$ \\
\hline $\begin{array}{l}\text { Al-Jasser } \\
\text { (2008) }\end{array}$ & $\begin{array}{l}\text { To investigate the ef- } \\
\text { fect of English phono- } \\
\text { tactic instruction on } \\
\text { lexical segmentation }\end{array}$ & $\begin{array}{l}\text { Pretest-treat- } \\
\text { ment-posttest }\end{array}$ & $\begin{array}{l}\text { 1. Use of Top-Up Listening } 3 \text { textbook with } \\
\text { listening clinic sections } \\
\text { 2. Assigned transcription tasks } \\
\text { 3. Explanation and memorization of conso- } \\
\text { nant cluster patterns } \\
\text { 4. Focus on illegal clusters } \\
\text { 5. Recognize and indicate illegal dusters }\end{array}$ \\
\hline $\begin{array}{l}\text { Yeldham and } \\
\text { Gruba (2014) }\end{array}$ & $\begin{array}{l}\text { To detail BU pro- } \\
\text { cessing development } \\
\text { of six learners }\end{array}$ & $\begin{array}{l}\text { Longitudinal } \\
\text { multi-case } \\
\text { studies }\end{array}$ & $\begin{array}{l}\text { 1. Identify aspects of reduced/connected } \\
\text { speech through transcription exercises } \\
\text { 2. Lexical segmentation practice, particu- } \\
\text { larly for parsing difficulties common to } \\
\text { Chinese learners of English } \\
\text { 3. Recognize intonational cues }\end{array}$ \\
\hline
\end{tabular}




\section{APPENDIX B}

\section{Dictation transcript}

Every day, I wake up at about 6 in the morning. I usually have coffee and toast for breakfast. I watch the news on TV a little and go to school. I use the train every day. I don't like taking the train. It takes about 90 minutes to get there. At school, I have lots of fun with my classmates, but our teacher gives us so much homework. Yesterday, I studied for 2 hours and I still wasn't finished. I hope the teacher doesn't get angry at me. Tonight, I'm going to work hard and finish my English report. 